\title{
An educational workshop designed for research ethics consultants to educate investigators on ethical considerations
}

\author{
Hiroaki Yanagawa ${ }^{1}$ (D) Masayuki Chuma ${ }^{1} \cdot$ Kenshi Takechi $^{1,2} \cdot$ Kenta Yagi $^{1}$. \\ Yasutaka Sato $^{1} \cdot$ Chikako Kane $^{1} \cdot$ Satoshi Sakaguchi ${ }^{1} \cdot$ Kaori Doi $^{3}$. \\ Yusuke Inoue $^{4} \cdot$ Kenji Matsui $^{5}$
}

Accepted: 25 September 2020 / Published online: 8 October 2020

C) The Author(s) 2020

\begin{abstract}
The role of research ethics consultants in biomedical research has increased to the point that they have an advisory capacity at all research institutes. For such professionals, we have established an educational system, which includes teaching materials, training methods, and nationwide educational workshops. These workshops have served to examine the developed system's usefulness and to provide realistic training for consultant candidates. In addition, we have used the current workshop to encourage clinical research investigators (and related personnel) to participate. Subsequently, we examined its usefulness as an opportunity to provide exposure to research ethics. In October 2019, we held a 1-day pilot workshop in Tokushima, Japan, which included a basic lecture in research ethics. During the lecture, two sets of materials were used for case discussion: case 1 , covering issues related to a clinical trial, and case 2 , covering issues related to human biological specimens. At the end of the workshop, a 30-item selfreporting anonymous questionnaire was provided. Of the 13 total participants, 9 (70\%) were clinical research investigators and related personnel, while $6(46 \%)$ had no direct intention to act as consultants. Respondents indicated that case 2 was more difficult than case 1 . However, both cases were generally accepted as educational materials; thus, satisfaction was expressed in relation to both. As the evaluations of the cases were generally positive, we will further examine the usefulness of participation in the workshop in the cultivation of research ethics in the investigator community.
\end{abstract}

Keywords Research ethics · Consultants · Education · Japan · Investigators

Electronic supplementary material The online version of this article (https://doi.org/10.1007/s40889-02000107-x) contains supplementary material, which is available to authorized users.

Hiroaki Yanagawa

niseko@ tokushima-u.ac.jp

Extended author information available on the last page of the article 


\section{Introduction}

Research ethics are central to biomedical research; thus, various attempts have been made to provide investigators and/or research ethics committee members with ethics-related methodological education (Halkoaho et al. 2013; Ramalingam et al. 2014; Millum et al. 2015). In the practice of ethical biomedical research, attention has recently shifted to the role of research ethics consultants. These consultants have the capacity to advise clinical research investigators at each research institute (Beskow et al. 2009; McCormick et al. 2013; Sharp et al. 2015; Porter et al. 2018a). Notably, despite investigator-directed research ethics education, there is a paucity of information concerning such initiatives for research ethics consultants (Arnold et al. 2018; Porter et al. 2018b).

Under the project titles "Research and development of model teaching material/ program for research ethics education" (2016-2018) and "Development of the comprehensive higher education programs on research ethics and integrity for medical sciences" (2019-2021), we are currently developing teaching materials/programs for research ethics education. These resources are mainly geared toward research ethics consultants. These projects are supported by Grant-in Aid from the Japan Agency for Medical Research and Development (AMED) (designated as AMED Matsui Projects in the present article; supervised by Kenji Matsui). Our materials/programs utilize education to equip consultants with knowledge and resources to provide practical advice for investigators based on a profound understanding of research ethics.

During the course of our project, we have conducted several workshops. Participant feedback allows us to gauge the usefulness of our education program. Following attendance of the workshop, participants are expected to fill the role of qualified and competent educators employing our materials. Thus, we recruited participants with basic knowledge of research ethics, related experience, and the desire to become consultants in their research institutes. An alternate function of these workshops is to extend opportunities for in-depth ethical research to investigators and clinical trialrelated personnel, such as clinical research coordinators (CRCs). In the past, we have encouraged consultants and their candidates to attend our workshops. However, in a workshop held in 2019, we actively encouraged the above-mentioned personnel and investigators to attend and obtained their perspectives regarding these workshops.

\section{Methods}

\section{Participants}

In October 2019, we conducted a 1-day pilot workshop in Tokushima, Japan. The event schedule appears in Table 1. After a basic lecture in research ethics, two sets of materials (case 1, covering issues related to a clinical trial, and case 2, covering issues related to human biological specimens) were utilized for case-based discussions, each facilitated in groups of fewer than five people. The materials (originally written in Japanese and translated into English by the authors) are provided as supplementary files.

These cases were developed by the AMED Matsui Projects, based on authentic prior consultations, which project representatives moderated to avoid disclosure of confidential information. After the case scenario was presented, participants were 
Table 1 Agenda on 1-day workshop held in October 2019

10:00-11:30 Opening remarks and expression of the purpose of the workshop in AMED Matsui Project Basic lecture on research ethics

12:30-14:00 Case-based discussion on case 1 covering issues related to a clinical trial*

14:15-16:15 Case-based discussion on case 2: covering issues related to human biological specimens**

16:15-16:30 Overall discussion and closing remarks

*Case 1

Consultation case from an investigator about a clinical trial of oral care in chemotherapy- and/or radiotherapy-treated cancer patients

Discussion guide for case 1

1. Select issues to examine the consultation case.

2. Examine issues selected by the participants.

3. Establish an answer to investigator (if time permits).

** Case 2

Consultation case from an investigator about appropriate use of biological specimens with broad consent as biobank samples

Discussion guide for case 2

1. Select issues to examine the consultation case.

2. Examine issues selected by the participants.

3. Examine issues already presented in the scenario.

4. Establish modified protocol based on the discussion.

5. Establish an answer to investigator (if time permits).

encouraged to consider the final consultation answer to be given to investigators through several steps along with mentors using the discussion guide shown in Table 1. Of the 13 participants, 9 (70\%) were clinical research investigators and related personnel (one physician, one dentist, two pharmacists, four nurses, and one clinical nutritionist), $8(62 \%)$ had no experience in consultation service, and $6(46 \%)$ had no direct intention to act as consultants.

Ethics approval was not sought for this study because the Ethical Guidelines for Medical and Health Research Involving Human Subjects of the Japanese Government (MHLV 2015) did not apply. That is, the study did not involve human subjects with the following purposes: obtaining knowledge to maintain and promote health; recovery from injury or disease; improving patients' quality of life; understanding the cause(s) and pathology of disease; improving measures to prevent injury and disease; improving measures for diagnosis and treatment; or confirming the validity of such measures.

\section{Design and questionnaire}

Using a cross-sectional study design, we examined the perspectives of workshop participants using a 30-item self-reporting anonymous questionnaire. This tool was established by the core members of AMED Matsui Projects. After evaluation by other members of the AMED Matsui Projects, the questionnaire was used in previous workshops. The questionnaire was written in Japanese and contained two parts for each case: (1) seven items regarding participants' level of achievement and (2) four 
items on the evaluation of materials and educational methods. An additional part was included for overall program evaluation; it contained seven items and one section to freely write comments regarding the program and the topic of research ethics education.

The workshop's purpose was not merely the acquisition of research ethics-related knowledge. Thus, the questionnaire was not used to assess the workshop's influence on knowledge levels. In nearly all questions $(n=27)$, a five-point scale was used (strongly agree, agree, neutral, disagree, and strongly disagree). For questions related to satisfaction level $(n=3)$, a ten-point scale was used $(10=$ highest, $1=$ lowest $)$.

The principal investigator (first author) explained the study outline (i.e., purpose and methods) to participants at the end of the workshop, and questionnaires were distributed. The principal investigator also explained that participation was voluntary and that declining to participate would cause them no disadvantage.

\section{Results}

\section{Participants' level of achievement in case 1 and case 2}

We examined participants' level of achievement in terms of extracting ethical issues, analyzing the extracted issues, and noticing additional and relevant information, capacity for critical thinking in daily work, and capacity for future education using the workshop material. As shown in Fig. 1, positive (agree and strongly agree) answers were more frequent in case 1, suggesting that participants found case 2 more difficult. This phenomenon was not observed in the overall satisfaction level regarding the case experience, as presented in Table 2.

\section{Evaluation of materials and educational methods in case 1 and case 2}

We examined participants' evaluations of materials and educational methods. This evaluation assessed difficulty, the effectiveness of group work, and the quality of the teaching material, along with its potential usefulness in participants' (future) teaching opportunities. As shown in Fig. 2, no homogeneity was observed among items in cases 1 and 2.

\section{General program evaluation and participant commentary}

Overall, the participants' satisfaction with the workshop was high, as shown in Fig. 3. The responses indicated that the 1-day duration was not enough for case-based discussion. In the section for general comments, one participant expressed the value of the deep ethical reflection offered by the workshop. Another individual expressed the desire for discussion time and more case-related lectures.

\section{Discussion}

To address the ethical aspects of biomedical research, attention has recently been devoted to preparing research ethics consultation services at the institute level. The same can be said for independent reviews undertaken by ethics committees. 


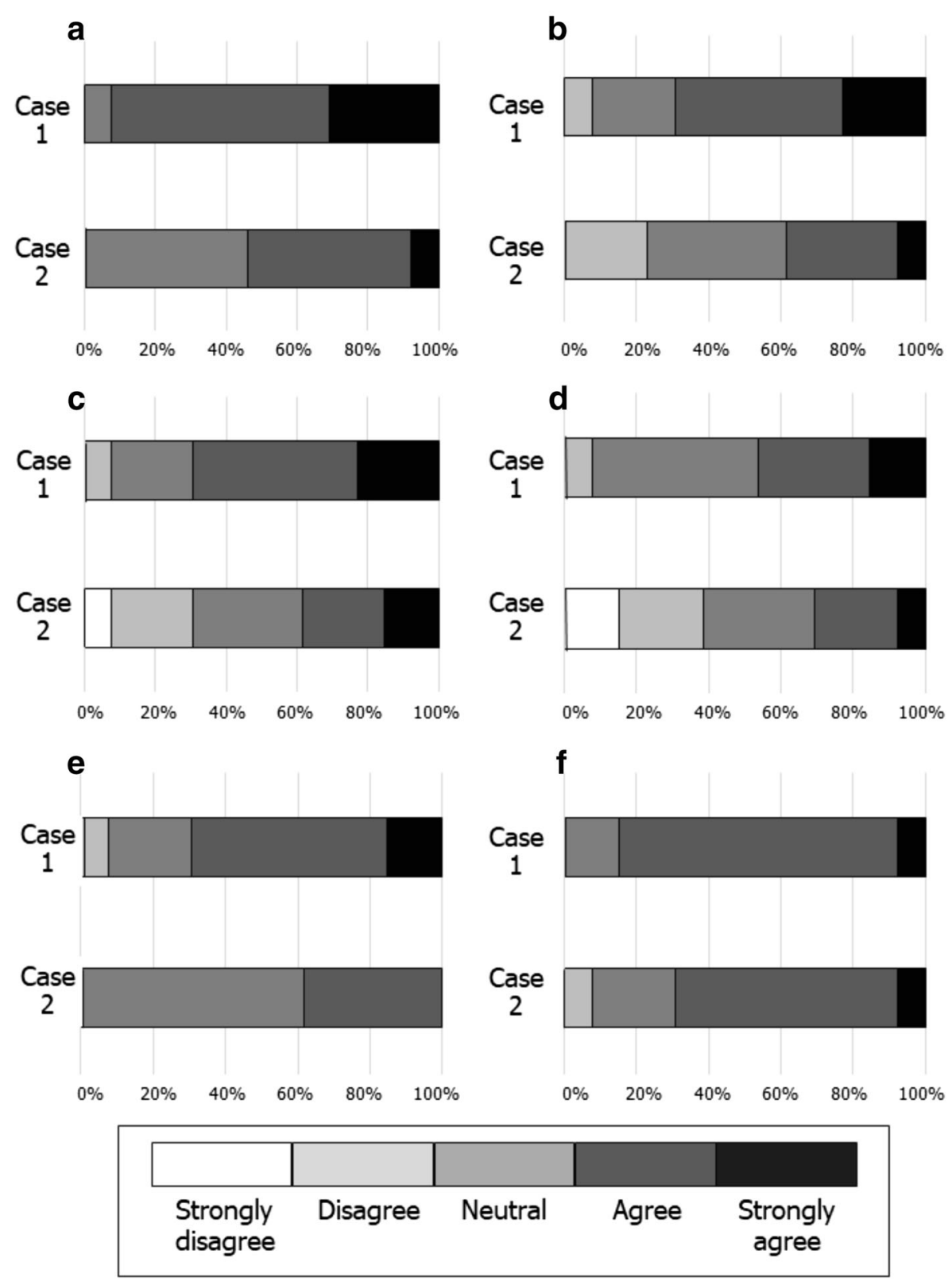

Fig. 1 Participants' recognition of the level of achievement. a I was able to extract ethical issues from the case presentation. b I was able to analyze the issues that I extracted. c I was able to find additional information needed to treat each case. $\mathbf{d}$ I was able to provide final advice to the investigator. e I was able to develop the practice of thinking deeply in daily work. $\mathbf{f}$ The experience is effective for undertaking future consultations

Nevertheless, educational materials/methods for training research ethics consultants remain limited. Furthermore, the competency of research ethics consultants is not well established. Thus, the AMED Matsui Projects examined educational materials/methods geared toward professional research ethics consultants. 
Table 2 Overall satisfaction level in group discussions of cases 1 and 2 and workshop program as a whole

\begin{tabular}{lllllllllllll}
\hline \multicolumn{1}{c}{ Number of participants } \\
\cline { 2 - 11 } Satisfaction level* & 1 & 2 & 3 & 4 & 5 & 6 & 7 & 8 & 9 & 10 & NA** $^{*}$ \\
\hline Group discussion of case 1 & 0 & 0 & 0 & 0 & 0 & 0 & 1 & 4 & 4 & 2 & 2 \\
Group discussion of case 2 & 0 & 0 & 0 & 0 & 1 & 0 & 2 & 2 & 3 & 3 & 2 \\
Workshop program as a whole & 0 & 0 & 0 & 0 & 0 & 0 & 0 & 3 & 5 & 3 & 2 \\
\hline
\end{tabular}

*1: lowest, 10: highest

**No answer

Notably, we have already proposed a competency model for research ethics consultants (Matsui et al. 2019). To reiterate our stance, however, we make the following points. Sharp et al. (2015) state that research ethics consultation should be provided by individuals with subject matter expertise derived from course work or personal experience. They also note that teaching research ethics to advanced students and prior scholarship in related fields are good indicators of such expertise. Bioethics faculty members and specialists in philosophy and sociology may be suitable candidates. People with scientific backgrounds, such as investigators, can also make good candidates if they master the required skills and knowledge. Personnel with basic knowledge (including regulations and guidelines), related experience, or the desire to become research ethics consultants in their institutes have been encouraged to participate in the AMED Matsui Projects workshops.

a

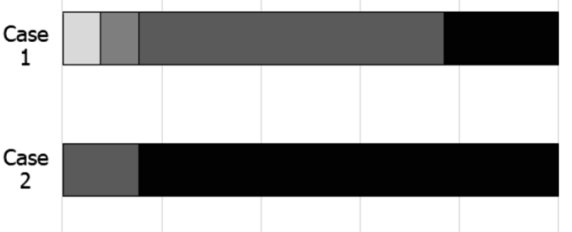

b

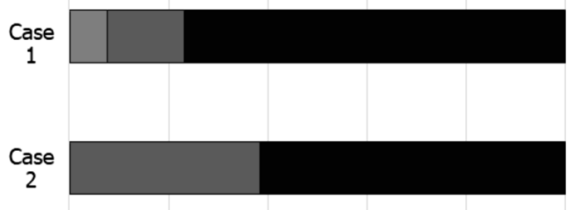

d

\section{C}
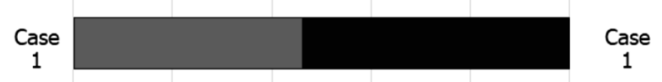

Case
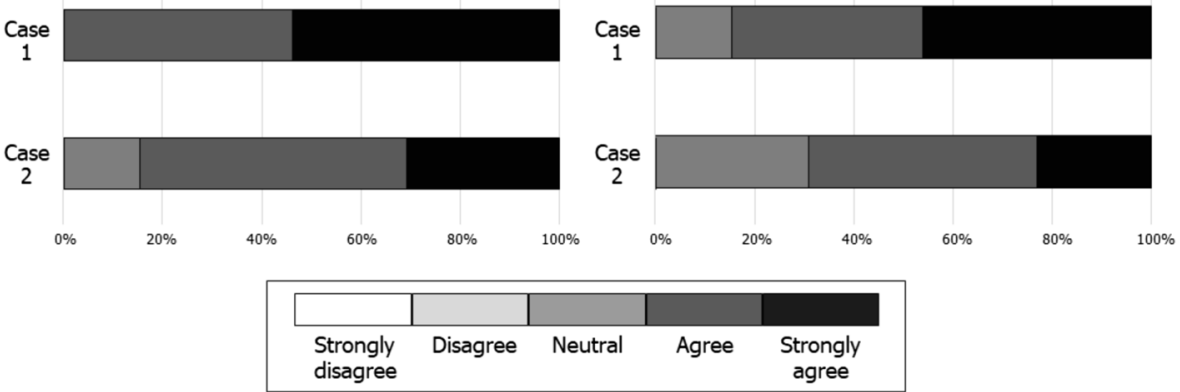

Fig. 2 Evaluation of the material and educational method of the workshop by participants. a The degree of difficulty was extremely high. b Group work was appropriate as an educational method. c The teaching material is appropriate. $\mathbf{d}$ The teaching material is suitable for their future teaching opportunities 
1) Bidirectional (interactive) program like today's is necessary for research ethics education.

2) Today's program was bidirectional (interactive).

3) The number of cases is satisfactory.

4) Time for group discussion is satisfactory.

5) Contents and material for group discussion are satisfactory.

6) I was able to understand the exact role of research ethics consultants.

7) The workshop was useful for future activities.

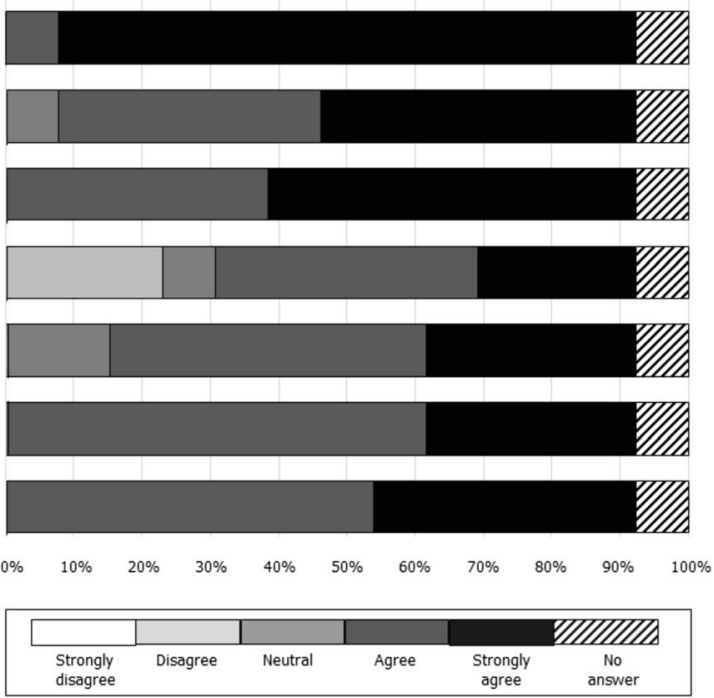

Fig. 3 Evaluation of the whole program by participants

We have already shared our 5-year experience of research ethics consultation at Tokushima University Hospital. Notably, a physician and scientists belonging to the clinical trial support section provided research ethics consultation (Yanagawa et al. 2018a). This is a common situation in Japan. In addition to the bioethics faculty, members of the clinical trial support section and even administrative office members mainly responded to inquiries from investigators (Kamisato et al. 2015; Aizawa et al. 2015). Clinical trial-related personnel, also common in Japan, such as CRCs, have been trained to promote clinical trials for drug approval (registration trials) (Yanagawa et al. 2018b). Consequently, and unavoidably, these personnel have had to manage queries from investigators (Yanagawa et al. 2018a). Therefore, such individuals - and investigators themselves - can be considered candidates for research ethics consultancy. Notably, however, the position of research ethics consultant is still limited in Japan, and most investigators hesitate to fill this role singlehandedly. Some may prefer to be investigators with considerable ability to perform ethics consultancy work. However, this work cannot be performed without due diligence. Indeed, one must consider human resource capacity, as well as the fact that the ethics and science of research are closely and inextricably related. The latter suggests that training investigators to be able to function dually as research ethics consultants may be a practical approach.

As shown in Fig. 1, case 2 seemed to be more difficult for the participants. Nine (70\%) of the 13 participants were clinical research investigators and related personnel, and 6 $(46 \%)$ had no direct intention to act as consultants. Therefore, the results, at least to some extent, reflect the perspective of clinical research investigators and related personnel. Moreover, they seem to be more familiar with clinical trials than biological materials. As the case evaluations were generally positive (see Figs. 1 and 2), we will proceed in a different direction. The next portion of this discussion considers the extent to which workshops can effectively cultivate research ethics in the investigator community.

It should be noted that this study has some limitations. It is a cross-sectional study based on a small sample. Moreover, the questionnaire contents might not account for 
the wide-ranging influences on education. Nevertheless, the tool provided us with basic information to explore investigators' and clinical research personnel's perceptions of the workshops. Because reports concerning research ethics consultant education are limited, such data may be valuable not only for us but also for those trying to establish a related educational system.

\section{Conclusion}

Although achievement levels were different in the two case-based discussions, clinical research investigators and related personnel seem to accept the present workshop as an opportunity to gain exposure to the topic. Indeed, the evaluations of the cases were generally positive. In the future, we plan to further examine the extent to which workshop participation supports the cultivation of research ethics in the investigator community. Further study is warranted to make an explicit determination regarding the usefulness of this education.

Acknowledgments The authors would like to thank the members of the AMED Matsui Projects for their encouragement and support.

Code availability Not applicable.

Authors' contributions All authors contributed jointly to the Matsui AMED Projects, including the present workshop. HY conceived this study, collected and analyzed data, and drafted the manuscript. MC, KT, KY, YS, CK, and SS collected data and participated in the study design. KD, YI, and KM participated in the study design and helped draft the manuscript. All authors have read and approved the final manuscript.

Funding This project was supported by the Japan Agency for Medical Research and Development under grants number (19oa0310003, 20oa0310003).

Data availability The datasets used during this study are available from the corresponding author upon reasonable request.

\section{Compliance with ethical standards}

Conflict of interest The authors declare that they have no conflict of interest.

Ethical approval Ethics approval was not sought for this study because the Ethical Guidelines for Medical and Health Research Involving Human Subjects of the Japanese Government (MHLW 2015) did not apply. That is, the study did not involve human subjects with the following purposes: obtaining knowledge to maintain and promote health; recovery from injury or disease; improving patients' quality of life; understanding the cause(s) and pathology of disease; improving measures to prevent injury and disease; improving measures for diagnosis and treatment; or confirming the validity of such measures.

Consent to participate After the principal investigator provided an explanation of the study outline at the end of the workshop, questionnaires were distributed. The workshop participants were asked to provide answers once they agreed to participate in the study.

Consent for publication Not applicable. 
Open Access This article is licensed under a Creative Commons Attribution 4.0 International License, which permits use, sharing, adaptation, distribution and reproduction in any medium or format, as long as you give appropriate credit to the original author(s) and the source, provide a link to the Creative Commons licence, and indicate if changes were made. The images or other third party material in this article are included in the article's Creative Commons licence, unless indicated otherwise in a credit line to the material. If material is not included in the article's Creative Commons licence and your intended use is not permitted by statutory regulation or exceeds the permitted use, you will need to obtain permission directly from the copyright holder. To view a copy of this licence, visit http://creativecommons.org/licenses/by/4.0/.

\section{References}

Aizawa, K., H. Nakada, K. Doi, T. Okita, and K. Matsui. 2015. The needs for research ethics consultation service in Japan: a preliminary questionnaire survey. Japanese Journal of Clinical Pharmacology and Therapeutics 46 (3): 115-125 (In Japanese).

Arnold, J.F., A.D. Boan, D.T. Lackland, and R.M. Sade. 2018. Clinical and translational research ethics: training consultants and biomedical research personnel. American Journal of Bioethics 18 (1): 57-61. https://doi.org/10.1080/15265161.2017.1401172.

Beskow, L.M., C. Grady, and B.S. Wilfond. 2009. Points to consider: the research ethics consultation service and the IRB. IRB 31 (6): 1-9.

Halkoaho, A., M. Matveinen, V. Leinonen, K. Luoto, and T. Keränen. 2013. Education of research ethics for clinical investigators with Moodle tool. BMC Medical Ethics 14 (1): 53. https://doi.org/10.1186/14726939-14-53.

Kamisato, A., S. Iwae, Y. Iijima, K. Aizawa, M. Suzuki, and K. Muto. 2015. Survey of "Research Ethics Support" for understanding current conditions and organizing the concept of support. Journal of Japan Association for Bioethics 25: 123-132 (In Japanese).

McCormick, J.B., R.R. Sharp, A.L. Ottenberg, C.R. Reider, H.A. Taylor, and B.S. Wilfond. 2013. The establishment of research ethics consultation services (RECS): an emerging research resource. Clinical and Translational Science 6 (1): 40-44. https://doi.org/10.1111/cts.12008 Epub 2012 Dec 6.

Matsui, K., Y. Inoue, H. Yanagawa, and T.A. Takano. 2019. A proposed model of core competencies required for research ethics consultants. Journal of Japan Association for Bioethics 29: 85-94 (In Japanese).

MHLW. 2015. Ethical guidelines for medical and health research involving human subjects. https:/www. mhlw.go.jp/file/06-Seisakujouhou-10600000-Daijinkanboukouseikagakuka/0000153339.pdf. . (In Japanese).

Millum, J., B. Sina, and R. Glass. 2015. International research ethics education. Journal of the American Medical Association 313 (5): 461-462. https://doi.org/10.1001/jama.2015.203.

Porter, K.M., M. Danis, H.A. Taylor, M.K. Cho, and B.S. Wilfond. 2018a. Clinical Research Ethics Consultation Collaborative Repository Group. The emergence of clinical research ethics consultation: insights from a national collaborative. American Journal of Bioethics 18 (1): 39-45. https://doi.org/10. 1080/15265161.2017.1401156.

Porter, K.M., M. Danis, H.A. Taylor, M.K. Cho, and B.S. Wilfond. 2018b. Defining the scope and improving the quality of clinical research ethics consultation: response to open peer commentaries about the national collaborative. American Journal of Bioethics 18 (2): W13-W15. https://doi.org/10.1080/15265161.2017. 1413438.

Ramalingam, S., S. Bhuvaneswari, and R. Sankaran. 2014. Ethics workshops-are they effective in improving the competencies of faculty and postgraduates? Journal of Clinical and Diagnostic Research 8: XC01XC03. https://doi.org/10.7860/JCDR/2014/8825.4561 Epub 2014 Jul 20.

Sharp, R.R., H.A. Taylor, M.A. Brinich, M.M. Boyle, M. Cho, M. Coors, M. Danis, M. Havard, D. Magnus, and B. Wilfond. 2015. Research ethics consultation: ethical and professional practice challenges and recommendations. Academic Medicine 90 (5): 615-620. https://doi.org/10.1097/ACM. 0000000000000640.

Yanagawa, H., R. Katashima, C. Sato, K. Takechi, H. Nokihara, C. Kane, M. Chuma, and Y. Aoe. 2018 a. Research ethics consultation: an attempt and 5-year experience in a Japanese University Hospital. $B M C$ Research Notes 11 (1): 665. https://doi.org/10.1186/s13104-018-3772-0.

Yanagawa, H., H. Nokihara, H. Yokoi, H. Houchi, M. Nagai, R. Yamashita, N. Suganuma, M. Hyodo, and the Shikoku Collaborative Group for Promotion of Clinical Trials. 2018b. Present status and perspectives on 
future roles of Japanese clinical research coordinators. Journal of Clinical Medicine Research 10 (12): 877-882. https://doi.org/10.14740/jocmr3602w Epub 2018 Oct 30.

Publisher's note Springer Nature remains neutral with regard to jurisdictional claims in published maps and institutional affiliations.

\section{Affiliations}

\section{Hiroaki Yanagawa ${ }^{1} \cdot$ Masayuki Chuma ${ }^{1} \cdot$ Kenshi Takechi ${ }^{1,2} \cdot$ Kenta Yagi $^{1}$ • Yasutaka Sato $^{1} \cdot$ Chikako Kane $^{1} \cdot$ Satoshi Sakaguchi $^{1} \cdot$ Kaori Doi $^{3} \cdot$ Yusuke Inoue $^{4} \cdot$ Kenji Matsui $^{5}$}

1 Clinical Research Center for Developmental Therapeutics, Tokushima University Hospital, 2-50-1 Kuramoto-cho, Tokushima City, Tokushima 770-8503, Japan

2 Division of Pharmaceutical Information Science, College of Pharmaceutical Sciences, Matsuyama University, Ehime, Japan

3 Department of Research Ethics \& Bioethics, National Cerebral and Cardiovascular Center Research Institute, Suita City, Osaka, Japan

4 Department of Public Policy, Institute of Medical Science, The University of Tokyo, Minato-ku, Tokyo, Japan

5 Division of Bioethics and Healthcare Law, National Cancer Center Japan, Chuo-ku, Tokyo, Japan 